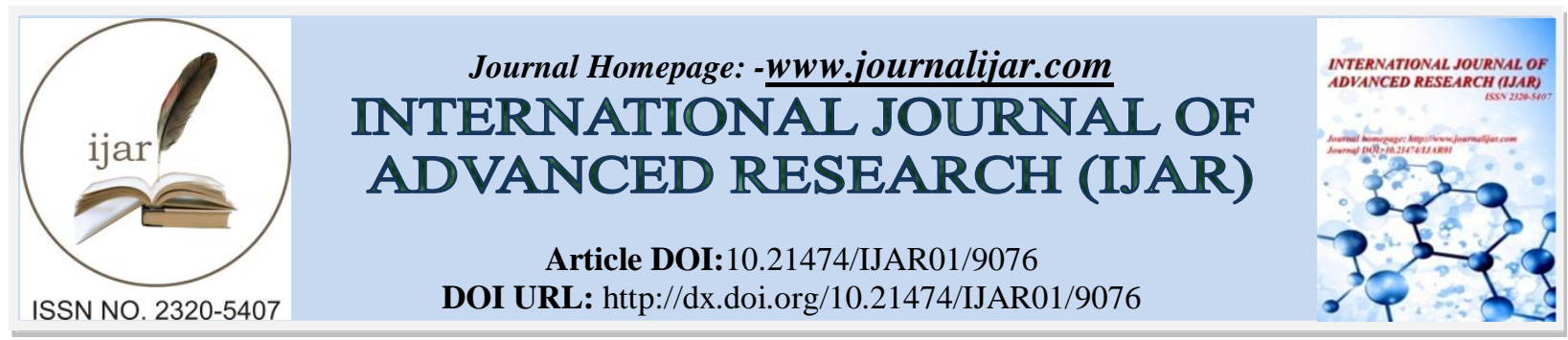

RESEARCH ARTICLE

\title{
MULTIDISCIPLINARY MANAGEMENT OF MALOCCLUSION DUE TO SUPERNUMERARY TOOTH -A CASE REPORT.
}

\section{Reena Rani,Sanjay Chachra,Abhishek Dhindsa,Samriti Bansal,Taranjot Kaur,Manu Sharma and Gurpreet Kour.}

\section{Manuscript Info}

\section{Manuscript History}

Received: 15 March 2019

Final Accepted: 17 April 2019

Published: May 2019

Key words:-

Axial inclination, Malocclusion, Rotation, Supernumerary tooth, Surgical.

\begin{abstract}
Supernumerary teeth are the most common developmental dental anomaly that has been argued to arise from multiple etiologies like hyperactivity of dental lamina, environmental factors dichotomy or polygenetic process of atavism. Supernumerary teeth present classical oral complication such as occlusal interference, diastema formation, delayed eruption, axial rotation/inclination of permanent teeth and crowding. The present case report describes the successful management of the malaligned teeth due to presence of supernumerary tooth. A combination of surgical and removable appliance was employed to correct the resulting malocclusion.
\end{abstract}

Copy Right, IJAR, 2019,. All rights reserved.

\section{Introduction:-}

Supernumerary tooth is a disorder of odontogenic origin resulting from the continuous budding of the enamel organ or from excessive proliferation of cells of dental lamina. It can be responsible for a variety of irregularities in the developing occlusion particularly the impaction or ectopic eruption of adjacent permanent teeth. ${ }^{1,2}$ According to its location, these are mesiodens, paramolar and distomolar. Mesiodens is the most common one. It is usually a small tooth with acone or peg shaped crown and a short root structure. When there is delay in eruption of the permanent incisors or if the central incisors are malposed or exhibit spacing and displaced/axially inclined, the presence of a mesiodens should be suspected. ${ }^{3,4}$ The overall prevalance of mesiodens is between $0.15 \%$ to $1.9 \%{ }^{3,8}$

It has been found that approximately $25 \%$ of the permanent supernumerary teeth are erupted and the remainder are unerupted, whereas $73 \%$ of the primary supernumerary teeth are erupted. ${ }^{9}$ Most of the problems associated with supernumerary tooth are related to alter growth and development in the area. Common sequelae comprises of overetention of primary teeth, impaction or delayed eruption of permanent teeth, dilacerations or abnormal root development of the maxillary incisors and/or abnormal crowding or spacing of the anterior teeth. Other less frequent problems include root resorption of adjacent teeth dentigerous cyst formation and nasal eruption of superneumarary teeth. ${ }^{3,5,6,7}$ When any of the above complication occurs or is anticipated, surgical removal of the supernumerary tooth is indicated.

This article will describe the surgical management of an erupted supernumerary tooth with midline diastema and interfering the eruption of maxillary central incisor. Subsequently removable appliance to align permanent maxillary central incisors in an occlusal plane. 


\section{Case Report}

A 9 year old child reported to the Department of Pedodontics and Preventive Dentistry with a chief complaint of proclined upper front teeth. On intraoral and radiographic (Figure 1) examination, a diagnosis of mesiodens was made.

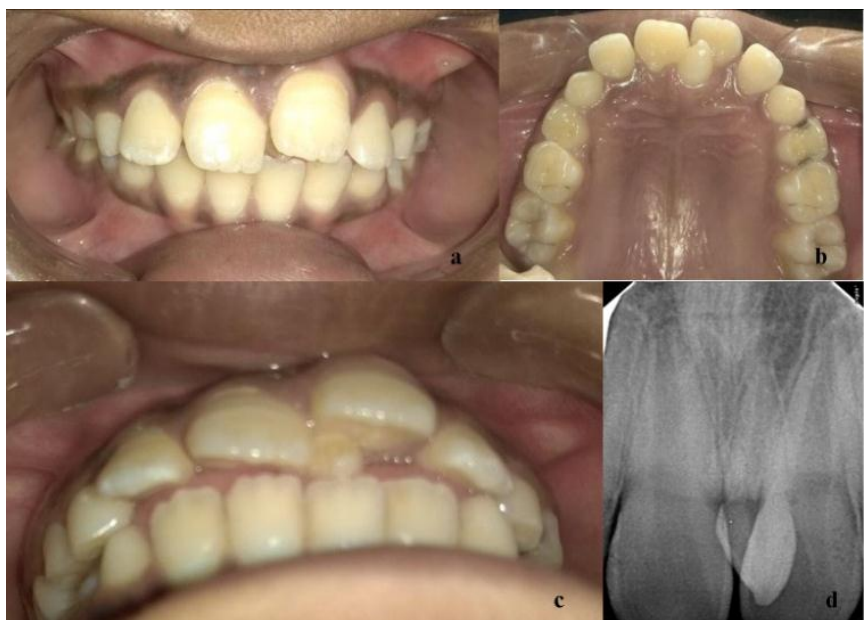

Figure 1:-(1a) Axial inclination of 21 (1b) Palatally presence of supernumerary tooth in relation to 21 (1c)Occlusal view depicting occlusal interference (1d) IOPAR revealing presence of supernumerary tooth between two central incisors

The patient's medical and dental history was non-contributory to the present condition and his family history of an additional teeth was also nonsignificant .The treatment goals were to extraction of mesiodens and to maintain the normal overjet and overbite. The extraction was carried out under local anesthesia and immediate post operative radiograph was taken to ensure that no tooth fragment has been left inside the socket.

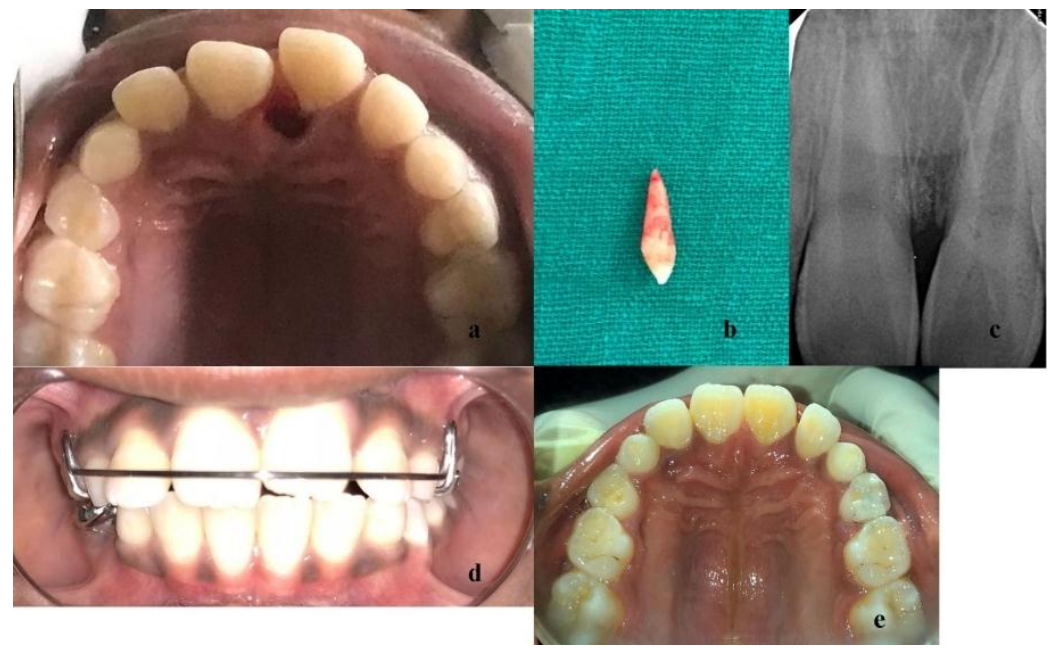

Figure 2:-(2a) Atraumatic extraction of supernumerary tooth,(2b) Extracted supernumerary tooth,(2c) Post operative IOPAR,(2d) Hawley's appliance insertion and (2e) Post operative aligned teeth

The patient was recalled after 7 days for further correction of labial inclination of 21 with removable Hawley's appliance which was activated after every 21 days and desired alignment of teeth was obtained in 3 months (figure 2) and appliance was then discontinued.

\section{Discussion:-}

Most cases of mesiodens are diagnosed during the first decade as this period coincides with the eruption time of maxillary central incisors and radiographic examinations are performed as an aid to screening for congenitally missing teeth, supernumerary teeth, cysts and tumors when delayed eruption or malposition of the maxillary central 
incisors are seen. ${ }^{10}$ If the permanent teeth have been displaced, surgical exposure, adjunctive periodontal surgery and, possibly,mechanical traction are likely to be required. Extraction should be completed as soon as the supernumerary teeth can be removed without harming the developing normal teeth. ${ }^{11}$

In the present Case, the supernumerary tooth was mesiodens. The most common complication of mesiodens is displacement of central incisors. ${ }^{12}$ The treatment was aimed at extraction of mesiodens followed by removable Hawley's appliance for minor orthodontic correction of 21.

\section{Conclusion:-}

Mesiodens in childhood is not a rare condition. Delayed, ectopic or asymmetric eruption of the central incisors should alert the clinician to the possibility of a mesiodens. To prevent complications and for timely surgical intervention, radiographic examination on a regular basis is highly recommended for the early diagnosis of a mesiodens.

\section{References:-}

1. Taner TU, Uzamis M. Orthodontic treatment of patient with multiple supernumerary teeth and mental retardation J Clin Pediatr Dent 1999;23:195-200.

2. Garvey MT, Barry HJ, Blake M. Supernumerary teeth: An overview of classification, Diagnosis and Management. J Can Dent Assoc 1999;65:612-6.

3. Primosch R. E. 'Anterior supernumerary teeth - Assessment and surgical intervention in children'. Pediatr. Dent 1981; 3(2): 204-215.

4. Russell KA, MagdalenaAFolwarczna. Mesiodens - Diagnosis and management of a common supernumerary tooth. J. Can DentAssoc 2003; 69(6): 362-6.

5. Henry R. J., P. A. Charles. A labially positioned mesiodens: Case report'. Ped. Dent. 1989. 11; 59-63

6. Smith R. A., C. C. Newton, S. G. Deluchi. 'Intranasal teeth’ Oral Med. 1979, 47: 120-122.

7. Tay F., A. Pang. S. Jaken. 'Unerupted maxillary anterior supernumerary teeth: report of 204 cases.' ASDC J. Dent. Child 1984. 51; 289-294

8. Sedano. H. O., R. J. Golin. Familial occurrence of mesiodens. 'Oral surg. Oral med. Oral pathol. 1969. 27(3); 360-362

9. Mittal M,Sultan A.Clinical management of supernumerary teeth: A repost of two cases.J Indian Soc Pedod Prev Dent 2010;28:219-22

10. Von Arx T. Anterior maxillary supernumerary teeth: a clinical and radiographic study.Aust Dent J 1992; 37: $189-195$.

11. Profitt WR, Fields HW, Sarver DM. Contemporary orthodontics. 4th ed. St Louis: CN Mosby Co; 1986. p. 138, 243

12. Hattab FN, Yassin OM, Rawashdeh MA. Supernumerary teeth: Report of three cases and review of the literature. J Dent Child 1994;61:382-93. 